\title{
Trends in Drug Costs and Overall Survival in Patients with Metastatic Non-small Cell Lung Cancer in The Netherlands Diagnosed from 2008 Through 2014
}

\author{
Christine M. Cramer-van der Welle ${ }^{1}$ (1) - Bas J. M. Peters ${ }^{2} \cdot$ Maarten J. Deenen $^{3}$ - Franz M. N. H. Schramel ${ }^{4}$. \\ Ewoudt M. W. van de Garde ${ }^{2,5}$
}

Published online: 12 June 2020

(c) The Author(s) 2020

\begin{abstract}
Background The Value-Based Health Care concept defines patient value as patient-relevant outcomes divided by costs. The aim of the present study was to assess the development of systemic treatment costs over the years compared with changes in overall survival (OS) at the level of a diagnosis of stage IV non-small cell lung cancer (NSCLC).

Methods All patients diagnosed (in 2008-2014) with stage IV NSCLC and treated with systemic treatment in six Dutch large teaching hospitals (Santeon network) were included. We collected data on OS and amounts of drug units (milligrams) for every drug in the applied systemic cancer treatments, until death. These amounts were multiplied by Dutch unit costs (Euros/mg) expressed in 2018 Euros to construct total drug costs per line of treatment per patient. Costs for day care visits were added for drugs requiring parenteral administration.

Results Data were collected from 1214 patients. Median OS and mean total drug costs showed no significant variation over the years ( $p=0.437$ and $p=0.693$, respectively). Mean total drug costs per 1 year of survival ranged from $€ 20,665$ to $€ 26,438$ during the period under study. Costs for first-line systemic treatment were significantly higher in 2011-2014 compared with 2008-2010.

Conclusion This study shows that overall drug costs were stable over the years, despite a relative increase in first-line treatment costs. Median OS remained at around 8 months from year to year. These trend data are very relevant as background for the assessment of costs and achieved outcomes in the more recent years.
\end{abstract}

\section{Introduction}

Non-small cell lung cancer (NSCLC) comprises $73 \%$ of lung cancer diagnoses in The Netherlands and is usually detected after the occurrence of regional or distant metastases. The

Christine M. Cramer-van der Welle

c.van.der.welle@antoniusziekenhuis.nl

1 Santeon Hospital Group, Herculesplein 38, 3584 AA Utrecht, The Netherlands

2 Department of Clinical Pharmacy, St. Antonius Hospital, Utrecht/Nieuwegein, The Netherlands

3 Department of Clinical Pharmacy, Catharina Hospital, Eindhoven, The Netherlands

4 Department of Pulmonary Diseases, St Antonius Hospital, Utrecht/Nieuwegein, The Netherlands

5 Division of Pharmacoepidemiology and Clinical Pharmacology, Department of Pharmaceutical Sciences, Utrecht University, Utrecht, The Netherlands overall 1-year survival rate of metastatic NSCLC (stage IV) in The Netherlands is only 23\% [1]. Treatment options for lung cancer have expanded in recent years with the arrival of targeted therapies and immunotherapies. Targeted agents for patients with epidermal growth factor receptor (EGFR) mutations and anaplastic lymphoma kinase (ALK) rearrangements have proved benefits in a small number of patients with NSCLC. More recently, immunotherapeutic agents directed on the programmed cell death-1 (PD-1) receptor or its ligand PD-L1 have demonstrated a broader benefit and durable responses in NSCLC [2]. However, concern is growing that the magnitude of the survival benefit from these new anticancer therapies does not justify its high prices [3-6]. Moreover, the benefits of new treatments might not be clinically meaningful to patients [7]. Kemp and Prasad stated that in many cases there is insufficient evidence to reliably make the assertion that treatments that fail to improve overall survival (OS), but do improve surrogate outcomes, may still have meaningful clinical benefit [8]. 


\section{Key Points for Decision Makers}

In contrast to previous studies, we report trends in systemic treatment costs and the corresponding overall survival (OS) achieved in consecutive years for patients with stage IV non-small cell lung cancer.

Total drug costs and OS showed no significant alteration over the years 2008-2014, despite a relative increase in first-line treatment costs.

These data are useful as a reference point to assess the merits of immunotherapy in terms of cost of illness and corresponding outcomes.

Although traditional single intervention cost-effectiveness studies based on clinical trial data are widely available [9, 10], observational data about the actual costs and OS outcomes associated with systemic treatment regimens for NSCLC in realworld are still scarce. Recently published research on treatment costs for stage IV NSCLC in real-world practice showed that these costs were substantial, despite the fact that the median OS benefit was poor [11]; however, follow-up time was limited and results over the years were lacking. In particular, trend data covering an extended period will be important as a reflection on the development of the costs of drugs and corresponding established outcomes informing future payer/policy decision making.

Recently, we have constructed a large real-world cohort with highly detailed data about systemic treatments and outcomes for patients diagnosed with stage IV NSCLC in The Netherlands in 2008-2014 [12]. The aim of the present study was to explore trends in systemic treatment costs for all patients with metastasized NSCLC and the corresponding OS achieved in consecutive years in this cohort.

\section{Methods}

\subsection{Study Population and Drug Use}

All newly diagnosed patients with stage IV NSCLC (in 2008-2014) who were treated with systemic anticancer treatment in six large Dutch teaching hospitals (Santeon network) were captured from the previously described cohort [12]. For each patient, we extracted type of drug, dose, date of administration, and administration route of all anticancer drugs, from the date of diagnosis until death, from the Santeon Farmadatabase (SFD), which includes detailed data about prescribed pharmacotherapy [13]. When necessary, additional data on systemic treatments was derived from individual patient files. Next, for parenteral drugs, the sum of all actual doses administered was calculated per regimen for each individual patient. For oral drugs, the dispensed number of units or end date and frequency were used to calculate the total number of units applied. In case of missing values in patients receiving parenteral drugs, these were imputed with mean values from patients with the same treatment. For oral drugs, we used standard doses (e.g. erlotinib $150 \mathrm{mg}$, gefitinib $250 \mathrm{mg}$ ) and mean number of treatment days per regimen in case of missing values.

\subsection{Patient Outcomes}

OS was calculated based on the time between the date of treatment start and the date of death (as derived from the Personal Records Database [BRP] of the Government of The Netherlands). Patients still alive at 31 January 2017 ( $n=59 ; 5 \%)$ were censored. Four of these patients were receiving active treatment at that time.

\subsection{Drug Costs}

Pharmacy purchase prices were extracted from the official price list that is published by Z-index.nl BV [14] in April in the respective years, including 6\% VAT ("Appendix"). In the case of more than one manufacturer, the lowest price per milligram was selected. Subsequently, the pharmacy purchase prices have been adjusted for inflation to reflect the 2018 price level (2018 Euros) using the general price index as published by Statistics Netherlands [15]. Costs per patient were calculated by multiplying the number of drugs applied (milligrams) by cost/milligram, expressed in Euros corresponding with the calendar years of drug treatment, for every drug in the applied systemic cancer treatments, until death.

In case of parenterally administered drugs, the costs for a day care visit were added per unique date of administration. Costs for day care visits were obtained from the Dutch manual for costing studies [16-18] and have been adjusted for inflation towards 2018 [15].

\subsection{Statistics}

Descriptive statistics were used to describe survival and costs. Costs were expressed as mean \pm standard deviation (SD), and OS as median (with $95 \%$ confidence interval), as obtained from a Kaplan-Meier survival analysis. Overall mean costs per year of diagnosis were calculated by dividing the total costs from patients with that same year of diagnosis by the total number of patients in that same year of diagnosis who started systemic treatment. Subsequently, overall mean 
costs were subdivided into mean costs per respective line of treatment to illustrate the relative contributions thereof to the total drug costs of illness over the years. To do so, the costs from that line of treatment were again divided by the total number of patients in that same year of diagnosis who started any systemic treatment. In addition, the absolute mean costs per line of treatment have been calculated for the entire cohort based on patients who actually received the corresponding line of treatment.

The analysis covered three parts: (1) variation in costs over the years; (2) variation in survival over the years; and (3) variation in the ratio between costs and median survival over the years. One-way analysis of variance (ANOVA) was applied to assess statistically significant differences in costs, and the log-rank test was applied to test for differences in survival. All statistical analyses were performed in IBM SPSS Statistics 24 (IBM Corporation, Armonk, NY, USA). A $p$ value $<0.05$ was considered statistically significant.

\section{Results}

Data were collected from 1214 patients with stage IV NSCLC and systemic treatment (see Table 1 for patient characteristics). The vast majority of patients ( $>90 \%)$ received a platinum-doublet or an EGFR inhibitor as first-line treatment (see Cramer et al. [12] for administration frequencies). Of these patients, 34\% received second-line systemic treatment and $8 \%$ received further line(s) of treatment. The most prevalent second-line treatments were docetaxel (29\%), pemetrexed (20\%), and erlotinib (19\%). Figure 1 shows the drug costs per patient (mean $\pm \mathrm{SD}$ ), survival curves, and ratio between costs and median survival categorized by year of diagnosis.
Imputation of missing values was applied in 62 patients (5\%). The mean costs for first-line treatment, second-line treatment, and overall were $€ 12,209, € 3043$, and $€ 16,116$, respectively.

Mean total drug costs (including parenteral administration) per 1 year of survival ranged from $€ 20,665$ to $€ 26,438$ during the period under study. No significant difference was found in overall mean costs over the years $(p=0.693)$. Costs for first-line systemic treatment were significantly higher in 2011-2014 compared with 2008-2010 ( $p=0.005)$ [pre and post introduction of maintenance therapy]. Median OS remained at approximately the same value from year to year, with a range from 7.3 to 8.7 months (log-rank test $p=0.437$ ).

\section{Discussion}

This study showed no significant alteration in total drug costs and OS for patients with stage IV NSCLC over the years; however, costs for first-line systemic treatment were higher in 2011-2014 compared with 2008-2010. The likely explanation for this increase in first-line costs is the introduction of pemetrexed maintenance in 2011 in The Netherlands after the publication of a randomized phase III trial of maintenance pemetrexed versus placebo by Ciuleanu et al. [21].

To the best of our knowledge, the data presented are the only data on drug costs and the relation with OS in metastatic NSCLC in consecutive years in The Netherlands.

Overall, the results regarding mean costs found in our study are in line with data from another study from The Netherlands. van der Linden et al. reported total mean drug costs of $€ 4970$ for stage IV patients with first-line chemotherapy or targeted therapy, including costs for day care [22]. Considering that they studied patients irrespective

Table 1 Baseline characteristics of real-world patients with metastatic non-small cell lung cancer and systemic treatment per year of diagnosis

\begin{tabular}{|c|c|c|c|c|c|c|c|c|}
\hline & 2008 & 2009 & 2010 & 2011 & 2012 & 2013 & 2014 & Overall \\
\hline Subjects & $122(10)$ & $151(12)$ & $172(14)$ & $183(15)$ & $195(16)$ & $199(16)$ & $192(16)$ & $1214(100)$ \\
\hline Age at diagnosis, in years & $61 \pm 10$ & $62 \pm 10$ & $63 \pm 10$ & $63 \pm 9$ & $64 \pm 10$ & $62 \pm 9$ & $64 \pm 9$ & $63 \pm 10$ \\
\hline Male & $71(58)$ & $87(58)$ & $104(60)$ & $102(56)$ & $101(52)$ & $115(58)$ & $111(58)$ & $691(57)$ \\
\hline Comorbidities, $\mathrm{CCI} \geq 1$ & $49(40)$ & $75(50)$ & $83(48)$ & $82(45)$ & $94(48)$ & $88(44)$ & $93(48)$ & $564(46)$ \\
\hline \multicolumn{9}{|l|}{ ECOG PS } \\
\hline $0-1$ & $101(83)$ & $130(86)$ & $125(73)$ & $166(91)$ & $152(78)$ & $185(93)$ & $165(86)$ & $1024(84)$ \\
\hline$\geq 2$ & $14(11)$ & $16(11)$ & $27(16)$ & $11(6)$ & $27(14)$ & $13(7)$ & $27(14)$ & $135(11)$ \\
\hline Missing & $7(6)$ & $5(3)$ & $20(12)$ & $6(3)$ & $16(8)$ & $1(1)$ & $0(0)$ & $55(5)$ \\
\hline \multicolumn{9}{|l|}{ Histology } \\
\hline Squamous & $19(16)$ & $25(17)$ & $32(19)$ & $29(16)$ & $24(12)$ & $30(15)$ & $35(18)$ & $194(16)$ \\
\hline Adenocarcinoma & $64(52)$ & $81(54)$ & $91(53)$ & $124(68)$ & $141(72)$ & $136(68)$ & $123(64)$ & $760(63)$ \\
\hline Large cell & $19(16)$ & $22(15)$ & $17(10)$ & $15(8)$ & $13(7)$ & $13(7)$ & $14(7)$ & $113(9)$ \\
\hline Other or NOS & $20(16)$ & $23(15)$ & $32(19)$ & $15(8)$ & $17(9)$ & $20(10)$ & $20(10)$ & 147 (12) \\
\hline
\end{tabular}

Data are expressed as $n(\%)$ or mean \pm standard deviation

CCI Charlson Comorbidity Index [19, 20], ECOG PS Eastern Cooperative Oncology Group Performance Status, NOS not otherwise specified 

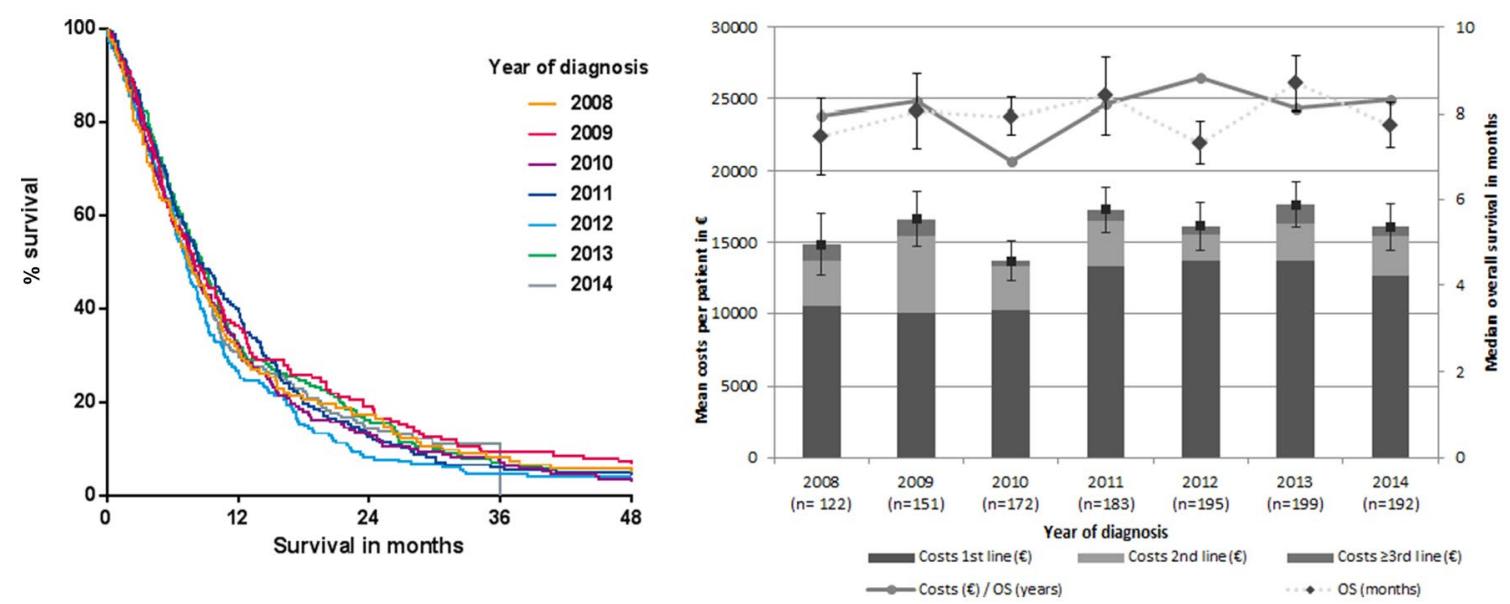

Fig. 1 Costs and survival in real-world patients with metastatic non-small cell lung cancer and systemic treatment diagnosed from 2008 through 2014. OS overall survival

of treatment (thus also including patients receiving supportive care only), and assuming that $55 \%$ of diagnosed patients receive supportive care only [12,23], this resembles total mean costs for first-line systemic treatment of $€ 11,044$, which is quite similar to our finding of mean drug costs of $€ 12,209$ for first-line systemic treatment. In contrast, our results differ substantially from the costs found by Keusters et al. [24]. This cost-of-illness study reported mean total costs of $€ 9427$ for oncolytic drugs and day care (the sum of $€ 6390 / 0.761$ and $€ 615 / 0.597$, respectively, when accounting for percentage of treated patients), which is much lower than our finding of mean total drug costs of $€ 16,116$. However, their research was performed in a tertiary cancer center and excluded all patients who were eligible for an ongoing clinical trial, which might have led to selection bias towards patients with poorer prognosis and earlier discontinuation of systemic treatment, and consequently less costs. Besides this, Keusters et al. showed that the average cost for metastatic NSCLC over time in The Netherlands has decreased (in 2006-2012 compared with 2003-2005), while expenses for oncolytic drugs rose. They expect that the trend of decreasing costs over time will not be representative, as immunomodulatory drugs will drive the trend in the opposite direction [12].

A strength of this study is the large and unselected population of real-world patients with detailed data regarding systemic treatments and actual doses for each individual patient. This means, for example, that early discontinuations and dose reductions are accounted for. Furthermore, by using historical drug list prices adjusted for inflation, our study reflects true alterations in treatment planning and incorporates price drops after expiration of patents, if any. Finally, this study is the first to report changes in systemic treatment costs over the years compared with changes in survival prognosis at the level of a diagnosis of stage IV NSCLC. The latter in contrast with a traditional health technology assessment, which are focused on the cost effectiveness of one or more unique interventions for these patients.

A limitation of this study could be our restriction to direct drug costs only. For example, we excluded other medical costs for lung cancer patients, such as outpatient visits, laboratory tests, visits to other healthcare providers, and treatments for adverse events. As a consequence, if newer, more expensive drugs cause less toxicity (thus saving costs for treatment of toxicity), this is not accounted for in our study. However, direct drug costs will give valuable insights when comparing standard chemotherapy with chemotherapy plus immunotherapy as a novel treatment option [25-27] in the assessment of costs and outcomes in more recent years. By adding immunotherapy to chemotherapy, net drug costs will increase while other costs and the toxicity profile remain more or less the same [28, 29].

Second, patients still alive at database closure could potentially have received further treatment $(n=4$ who were still receiving active treatment and could possibly start a new line of treatment in the future), of which the costs are not captured in this study, thus resulting in an underestimation of mean total costs. Another reason for underestimation of costs could be that patients moved to another site of care after completion of treatment, with the risk of unknown subsequent lines of treatment before death. However, due to the 
small number of patients still alive $(<5 \%)$ and the virtually complete first-line costs for these patients, which account for the largest part of total mean costs, those limitations will only cause a small underestimation.

Third, one could argue about changes in OS as a sole measure for benefit from systemic treatment. Measures on quality of life $(\mathrm{QoL})$ could also be informative to assess the benefit from systemic treatments over the years. However, OS remains an objective outcome since it represents survival time, a direct and unambiguous patient benefit. Furthermore, several challenges in measuring QoL exist regarding patient follow-up in the palliative phase. Finally, a limitation could be that novel treatment options such as immunotherapy were not covered by the time frame under study. Notwithstanding, this study provides insights into the costs for systemic treatments in the preimmunotherapy period and could serve as an important reference point to assess the economic impact of immunotherapy.

In a few years' time, a follow-up study can show how the costs and survival benefit ratio continues. Considering patient value as seen with the Value-Based Health Care concept [30], the ratio between outcomes and costs should increase. When studying this, it is important to consider that many countries have confidential discounts on newer biological therapies nowadays. In the end, the development of drug costs per patient with metastatic NSCLC will be the result of the interplay between new (more) expensive and effective treatments coming to market and potential price drops linked to the introduction of generics and biosimilars [31].

\section{Conclusions}

Overall costs for systemic drug treatment in patients with metastatic NSCLC were stable over the years 2008-2014, despite a relative increase in first-line treatment costs from 2011 onwards. Furthermore, OS in the corresponding years showed no improvements so far. These trend data are very relevant as background for the assessment of costs and achieved outcomes in more recent years, with newer treatment options available. Following the Value-Based Health Care theory, two times more/better outcomes would allow, at maximum, a doubling of the costs of delivering these outcomes to keep value at the status quo.
Author Contributions CC, BP, FS, and EvdG were involved in the conception and study design; EvdG conducted the study supervision; CC and $\mathrm{BP}$ were responsible for the acquisition of data; CC, BP, MD, FS, and EvdG were responsible for data analysis and interpretation; and $\mathrm{CC}, \mathrm{BP}$, and $\mathrm{MD}$ were responsible for the preparation and writing of the manuscript. All authors contributed to the manuscript and approved the final version.

\section{Compliance with Ethical Standards}

Funding None.

Conflict of interest Christine M. Cramer-van der Welle, Bas J. M. Peters, Maarten J. Deenen, Franz M. N. H. Schramel, and Ewoudt M. W. van de Garde declare they have no conflicts of interest.

Ethics approval This study was approved by a Medical Research Ethics Committee (CMO registration number 2016-2658), with need for informed consent being waived because of the retrospective nature of the study and anonymous handling of data.

Consent Not applicable.

Data and/or code availability The datasets generated and/or analyzed during this study are not publicly available but can be obtained from the corresponding author upon reasonable request.

Open Access This article is licensed under a Creative Commons Attribution-NonCommercial 4.0 International License, which permits any non-commercial use, sharing, adaptation, distribution and reproduction in any medium or format, as long as you give appropriate credit to the original author(s) and the source, provide a link to the Creative Commons licence, and indicate if changes were made. The images or other third party material in this article are included in the article's Creative Commons licence, unless indicated otherwise in a credit line to the material. If material is not included in the article's Creative Commons licence and your intended use is not permitted by statutory regulation or exceeds the permitted use, you will need to obtain permission directly from the copyright holder. To view a copy of this licence, visit http://creativecommons.org/licenses/by-nc/4.0/.

\section{Appendix}

See Table 2. 
Table 2 Unit costs per mg drug per year

\begin{tabular}{|c|c|c|c|c|c|c|c|c|c|}
\hline & 2008 & 2009 & 2010 & 2011 & 2012 & 2013 & 2014 & 2015 & 2016 \\
\hline Pemetrexed & 4.25 & 4.20 & 3.53 & 3.15 & 3.05 & 3.06 & 3.02 & 3.01 & 3.06 \\
\hline Bevacizumab & 4.14 & 4.04 & 3.79 & 3.73 & 3.62 & 3.60 & 3.50 & 3.45 & 3.57 \\
\hline Carboplatin & 0.90 & 0.89 & 0.88 & 0.86 & 0.84 & 0.27 & 0.26 & 0.26 & 0.26 \\
\hline Cisplatin & 1.07 & 1.06 & 0.82 & 0.56 & 0.56 & 0.52 & 0.51 & 0.51 & 0.51 \\
\hline Docetaxel & 11.75 & 11.19 & 10.55 & 4.50 & 4.39 & 4.28 & 5.24 & 5.21 & 5.19 \\
\hline Etoposide & 0.21 & 0.20 & 0.20 & 0.20 & 0.19 & 0.17 & 0.16 & 0.16 & 0.15 \\
\hline Gemcitabin & 0.26 & 0.24 & 0.11 & 0.11 & 0.10 & 0.05 & 0.05 & 0.05 & 0.05 \\
\hline Paclitaxel & 0.98 & 0.97 & 0.96 & 0.93 & 2.82 & 2.75 & 2.72 & 2.71 & 2.70 \\
\hline Vinorelbin & 2.30 & 2.27 & 2.24 & 2.19 & 2.14 & 2.08 & 2.56 & 2.53 & 2.53 \\
\hline Erlotinib & 0.60 & 0.59 & 0.57 & 0.57 & 0.54 & 0.53 & 0.53 & 0.53 & 0.55 \\
\hline Gefitinib & $\mathrm{n} / \mathrm{a}$ & $\mathrm{n} / \mathrm{a}$ & 0.42 & 0.39 & 0.38 & 0.38 & 0.37 & 0.37 & 0.38 \\
\hline Afatinib $^{a}$ & $\mathrm{n} / \mathrm{a}$ & $\mathrm{n} / \mathrm{a}$ & $\mathrm{n} / \mathrm{a}$ & $\mathrm{n} / \mathrm{a}$ & $\mathrm{n} / \mathrm{a}$ & 95.64 & 93.54 & 91.84 & 90.04 \\
\hline Crizotinib & $\mathrm{n} / \mathrm{a}$ & $\mathrm{n} / \mathrm{a}$ & $\mathrm{n} / \mathrm{a}$ & $\mathrm{n} / \mathrm{a}$ & $\mathrm{n} / \mathrm{a}$ & 0.40 & 0.40 & 0.40 & 0.39 \\
\hline Ceritinib & $\mathrm{n} / \mathrm{a}$ & $\mathrm{n} / \mathrm{a}$ & $\mathrm{n} / \mathrm{a}$ & $\mathrm{n} / \mathrm{a}$ & $\mathrm{n} / \mathrm{a}$ & $\mathrm{n} / \mathrm{a}$ & $\mathrm{n} / \mathrm{a}$ & $\mathrm{n} / \mathrm{a}$ & 0.30 \\
\hline Nintedanib & $\mathrm{n} / \mathrm{a}$ & $\mathrm{n} / \mathrm{a}$ & $\mathrm{n} / \mathrm{a}$ & $\mathrm{n} / \mathrm{a}$ & $\mathrm{n} / \mathrm{a}$ & $\mathrm{n} / \mathrm{a}$ & $\mathrm{n} / \mathrm{a}$ & 0.31 & 0.31 \\
\hline Osimertinib $^{\mathrm{a}}$ & $\mathrm{n} / \mathrm{a}$ & $\mathrm{n} / \mathrm{a}$ & $\mathrm{n} / \mathrm{a}$ & $\mathrm{n} / \mathrm{a}$ & $\mathrm{n} / \mathrm{a}$ & $\mathrm{n} / \mathrm{a}$ & $\mathrm{n} / \mathrm{a}$ & $\mathrm{n} / \mathrm{a}$ & 222.27 \\
\hline
\end{tabular}

Data are presented as $€$ per mg drug including VAT and inflation rates

${ }^{a}$ Fixed price per day, dose independent

\section{References}

1. The Netherlands Cancer Registry. www.cijfersoverkanker.nl. Accessed 13 Nov 2018.

2. Naylor EC, Desani JK, Chung PK. Targeted therapy and immunotherapy for lung cancer. Surg Oncol Clin N Am. 2016;25(3):601-9.

3. Del Paggio JC, Sullivan R, Schrag D, Hopman WM, Azariah B, Pramesh CS, et al. Delivery of meaningful cancer care: a retrospective cohort study assessing cost and benefit with the ASCO and ESMO frameworks. Lancet Oncol. 2017;18(7):887-94.

4. Cohen D. Cancer drugs: high price, uncertain value. BMJ. 2017;359:j4543.

5. Jiang DM, Chan KKW, Jang RW, Booth C, Liu G, Amir E, et al. Anticancer drugs approved by the Food and Drug Administration for gastrointestinal malignancies: clinical benefit and price considerations. Cancer Med. 2019;8(4):1584-93.

6. Kantarjian HM, Fojo T, Mathisen M, Zwelling LA. Cancer drugs in the United States: Justum Pretium - the just price. J Clin Oncol. 2013;31(28):3600-4.

7. Davis C, Naci H, Gurpinar E, Poplavska E, Pinto A, Aggarwal A. Availability of evidence of benefits on overall survival and quality of life of cancer drugs approved by European Medicines Agency: retrospective cohort study of drug approvals 2009-13. BMJ. 2017;359:j4530.

8. Kemp R, Prasad V. Surrogate endpoints in oncology: when are they acceptable for regulatory and clinical decisions, and are they currently overused? BMC Med. 2017;15(1):134.

9. Bongers ML, Coupe VM, Jansma EP, Smit EF, Uyl-de Groot CA. Cost effectiveness of treatment with new agents in advanced nonsmall-cell lung cancer: a systematic review. Pharmacoeconomics. 2012;30(1):17-34

10. Nguyen CTT, Petrelli F, Scuri S, Nguyen BT, Grappasonni I. A systematic review of pharmacoeconomic evaluations of erlotinib in the first-line treatment of advanced non-small cell lung cancer. Eur J Health Econ. 2016;20(5):763-77.
11. Seung SJ, Hurry M, Hassan S, Walton RN, Evans WK. Cost-ofillness study for non-small-cell lung cancer using real-world data. Curr Oncol. 2019;26(2):102-7.

12. van der Welle CMC, Peters BJM, Schramel F, Klungel OH, Groen HJM, Santeon NSCLC Study Group. Systematic evaluation of the efficacy-effectiveness gap of systemic treatments in metastatic nonsmall cell lung cancer. Eur Respir J. 2018;52(6):1801100.

13. van de Garde EMW, Plouvier BC, Fleuren H, Haak EAF, Movig KLL, Deenen MJ, et al. Pharmacotherapy within a learning healthcare system: rationale for the Dutch Santeon Farmadatabase. Eur J Hosp Pharm. 2019;26(1):46-50.

14. Z-index BV. https://www.z-index.nl/english. Accessed 27 May 2019.

15. CBS StatLine. https://statline.cbs.nl/Statweb/?LA=en. Accessed 28 Jan 2019.

16. Institute for Medical Technology Assessment. Dutch manual for costing studies. Rotterdam: Erasmus Universiteit Rotterdam; 2015.

17. Kanters TA, Bouwmans CAM, van der Linden N, Tan SS, van Roijen LH. Update of the Dutch manual for costing studies in health care. PLoS One. 2017;12(11):e0187477.

18. Tan SS, Van Gils CW, Franken MG, van Roijen LH, Uyl-de Groot CA. The unit costs of inpatient hospital days, outpatient visits, and daycare treatments in the fields of oncology and hematology. Value Health. 2010;13(6):712-9.

19. Charlson ME, Pompei P, Ales KL, MacKenzie CR. A new method of classifying prognostic comorbidity in longitudinal studies: development and validation. J Chronic Dis. 1987;40(5):373-83.

20. Sundararajan V, Henderson T, Perry C, Muggivan A, Quan H, Ghali WA. New ICD-10 version of the Charlson comorbidity index predicted in-hospital mortality. J Clin Epidemiol. 2004;57(12):1288-94.

21. Ciuleanu T, Brodowicz T, Zielinski C, Kim JH, Krzakowski M, Laack E, et al. Maintenance pemetrexed plus best supportive care versus placebo plus best supportive care for non-small-cell lung cancer: a randomised, double-blind, phase 3 study. Lancet. 2009:374(9699):1432-40. 
22. van der Linden N, Bongers ML, Coupe VM, Smit EF, Groen HJ, Welling A, et al. Costs of non-small cell lung cancer in the Netherlands. Lung Cancer. 2016;91:79-88.

23. Peters BJM, Cramer-Vd Welle CM, Smit AAJ, Schramel F, van de Garde EMW, Santeon NSCLC Study Group. Trends in prescribing systemic treatment and overall survival for non-small cell lung cancer stage IIIB/IV in the Netherlands: 2008-2012. Cancer Epidemiol. 2017;51:1-6.

24. Keusters WR, de Weger VA, Hovels A, Schellens JHM, Frederix GWJ. Changing costs of metastatic non small cell lung cancer in the Netherlands. Lung Cancer. 2017;114:56-61.

25. Gandhi L, Rodriguez-Abreu D, Gadgeel S, Esteban E, Felip E, De Angelis F, KEYNOTE-189 Investigators, et al. Pembrolizumab plus chemotherapy in metastatic non-small-cell lung cancer. $\mathrm{N}$ Engl J Med. 2018;378(22):2078-92.

26. Paz-Ares L, Luft A, Vicente D, Tafreshi A, Gumus M, Mazieres J, KEYNOTE-407 Investigators, et al. Pembrolizumab plus chemotherapy for squamous non-small-cell lung cancer. N Engl J Med. 2018;379(21):2040-51.

27. Socinski MA, Jotte RM, Cappuzzo F, Orlandi F, Stroyakovskiy D, Nogami N, I.M.S. Group, et al. Atezolizumab for first-line treatment of metastatic nonsquamous NSCLC. N Engl J Med. 2018;378(24):2288-301.

28. Luo W, Wang Z, Tian P, Li W. Safety and tolerability of PD-1/ PD-L1 inhibitors in the treatment of non-small cell lung cancer: a meta-analysis of randomized controlled trials. J Cancer Res Clin Oncol. 2018;144(10):1851-9.

29. Magee DE, Hird AE, Klaassen Z, Sridhar SS, Nam RK, Wallis CJD, et al. Adverse event profile for immunotherapy agents compared with chemotherapy in solid organ tumors: a systematic review and meta-analysis of randomized clinical trials. Ann Oncol. 2020;31(1):50-60.

30. Porter ME. What is value in health care? N Engl J Med. 2010;363(26):2477-81.

31. Godman B, Hill A, Simeons S, Baker A, Gulbinovic J, Martin AP, et al. Pricing of oral generic cancer medicines in 25 European countries: findings and implications. Generics Biosim Initiat J. 2019;8(2):49-70. 